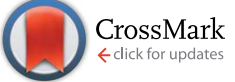

Cite this: RSC Adv., 2014, 4, 49161

Received 12th August 2014 Accepted 26th September 2014

DOI: $10.1039 / c 4 r a 08555 h$

www.rsc.org/advances

\section{Nitrogen-doped activated carbon as a metal free catalyst for hydrogen production in microbial electrolysis cells $\uparrow$}

\author{
Bo Zhang, ${ }^{a}$ Zhenhai Wen, ${ }^{b}$ Suqin $\mathrm{Ci}^{\mathrm{b}}{ }^{\mathrm{b}}$ Junhong Chen ${ }^{\star \mathrm{b}}$ and Zhen $\mathrm{He}^{\star \mathrm{c}}$
}

\begin{abstract}
Nitrogen-doped activated carbon was investigated as an alternative cathode catalyst for hydrogen production in microbial electrolysis cells (MECs). Both electrochemical and MEC tests confirmed that nitrogen doping was an effective method in improving the catalytic activity of activated carbon towards the hydrogen evolution reaction (HER). This improvement was attributed to the increased nitrogen content in activated carbon, as a higher content of nitrogen would facilitate the Volmer step in HER. Although the overall performance of the nitrogen-doped activated carbon was lower than the platinumbased catalysts, its low cost and (potentially) long-term stability would compensate for a low hydrogen production rate.
\end{abstract}

\section{Introduction}

A microbial electrolysis cell (MEC) is an electrochemical device that produces hydrogen gas with the help of electrochemicallyactive bacteria. ${ }^{1}$ In a typical MEC, the anodic bacteria utilize the anode as an electron acceptor during metabolism of organic matter present in wastewater. The electrons released from the oxidation process travel through an external circuit to a cathode electrode, which reduces protons to hydrogen gas. An external voltage $>0.2 \mathrm{~V}$ is usually required to overcome the thermodynamic barrier for the hydrogen evolution reaction (HER). ${ }^{2}$

HER requires the aid of catalysts, and the most widely used HER catalyst in MEC is platinum (Pt). However, due to the scarcity and high cost of Pt, it is not economically feasible to use Pt-based catalysts in large-scale MEC systems for deployment in wastewater treatment. ${ }^{3}$ Therefore, the search for alternative and

${ }^{a}$ Key Laboratory of Environmental Biotechnology, Research Center for Eco-Environmental Sciences, Chinese Academy of Science, Beijing 100085, China

${ }^{b}$ Department of Mechanical Engineering, University of Wisconsin-Milwaukee, Milwaukee, WI 53211, USA. E-mail: jhchen@uwm.edu

${ }^{c}$ Department of Civil and Environmental Engineering, Virginia Polytechnic Institute and State University, Blacksburg, VA 24061, USA. E-mail: zhenhe@vt.edu

$\uparrow$ Electronic supplementary information (ESI) available: SEM image of the ACN and AC. See DOI: 10.1039/c4ra08555h low cost cathode HER catalyst is one of the most important tasks that must be addressed towards MEC development. ${ }^{4}$ Indeed, various alternative cathode HER catalysts have been examined in MECs. ${ }^{4,5}$ However, the congeners of Pt, such as $\mathrm{Pd}^{\mathbf{6}}$ and $\mathrm{Ni}^{7}$ are still costly for wastewater treatment application, and the compounds of other metals, such as $\mathrm{MoS}_{2}{ }^{\mathbf{8 , 9}}$ and nanostructured iron, ${ }^{\mathbf{1 0}}$ lack the stability and usually involve a complex procedure of preparation.

It is well documented that the HER involves several independent steps: ${ }^{11}$

$$
\begin{gathered}
\text { Volmer step: } \mathrm{H}_{\mathrm{ad}} \leftrightarrow \mathrm{H}^{+}+\mathrm{e}^{-} \\
\text {Heyrovsky step: } \mathrm{H}_{2} \leftrightarrow \mathrm{H}_{\mathrm{ad}}+\mathrm{H}^{+}+\mathrm{e}^{-} \\
\text {Tafel step: } \mathrm{H}_{2} \leftrightarrow 2 \mathrm{H}_{\mathrm{ad}}
\end{gathered}
$$

It has been confirmed theoretically that the nitrogen doping would increase the electron densities in some of the adjacent carbon atoms and make them more readily to donate electrons. ${ }^{12}$ Therefore, it is reasonable to expect that the chemisorption of $\mathrm{H}^{+}$, i.e., the Volmer step of hydrogen generation, could be accelerated if nitrogen doped carbon materials are used as a catalyst for HER. However, on the other hand, the enhanced stability of $\mathrm{H}_{\mathrm{ad}}$ formed may in turn inhibit the following steps in the hydrogen generation. Thus, it is worth investigating whether nitrogen doping is a feasible method that can effectively enhance the catalytic activity of carbon materials in catalyzing the hydrogen production.

Previously, we have shown that nitrogen doping could significantly increase the catalytic activity of activated carbon (AC) towards oxygen reduction reaction. ${ }^{13}$ Because $\mathrm{AC}$ is commercially available in bulk quantity at a relatively low price, it has been widely used in water treatment ${ }^{14}$ and wastewater treatment processes. ${ }^{15}$ However, to our best knowledge, there have not been any studies of examining AC or its derivatives for hydrogen generation in an MEC. In this study, we have evaluated the nitrogen doped $\mathrm{AC}\left(\mathrm{AC}_{\mathrm{N}}\right)$ as a metal-free catalyst for 
hydrogen production in both electrochemical cells and MECs, and compared its performance with the Pt-based catalysts and pristine AC.

\section{Methods and materials}

\subsection{The preparation of the catalyst}

The $\mathrm{AC}_{\mathrm{N}}$ was synthesized according to the methods described in our previous work. ${ }^{13}$ The commercially available activated carbon (Fisher Scientific, Bridgewater, NJ, USA) was used as a base material. To better facilitate the nitrogen doping process, the AC was sequentially treated with acidic and alkaline solutions. During the acidic pretreatment process, two grams of AC powder was added into a solution containing $25 \mathrm{~mL}$ of $\mathrm{H}_{2} \mathrm{SO}_{4}$ (98\%) and 2 grams of $\mathrm{KMnO}_{4}$, and mixed for 3 hours. Then, the acid treated AC was washed thoroughly using DI water. After that, the acid pretreated $\mathrm{AC}$ was further treated in a $3 \mathrm{M} \mathrm{KOH}$ solution at $180{ }^{\circ} \mathrm{C}$ for 10 hours; the acid-alkaline pretreated AC was then thoroughly washed with DI water and used in the following nitrogen doping.

A solid state nitrogen precursor, cyanamide (Sigma-Aldrich, St. Louis, MO, USA), was used as a nitrogen source for nitrogen doping. The acid-alkaline pretreated AC and the cyanamide powder were mixed in 1 : 5 (mass ratio) and loaded into a programmable tube furnace (Lindberg, Thermo Scientific, USA). The tube furnace was flushed with argon gas for 10 min before the doping to ensure an inert atmosphere. During the doping process, the tube was flushed with argon gas at a flow rate of $0.1 \mathrm{~mL} \mathrm{~s}^{-1}$ continuously. The temperature of the furnace was increased from the room temperature to $80^{\circ} \mathrm{C}$ in 10 min and maintained at $80^{\circ} \mathrm{C}$ for $1 \mathrm{~h}$; then the temperature was further increased to $750{ }^{\circ} \mathrm{C}$ in $4 \mathrm{~h}$ and maintained at $750{ }^{\circ} \mathrm{C}$ for additional $2 \mathrm{~h}$.

\subsection{Electrochemical characterization}

Linear sweep voltammetry (LSV) was conducted to evaluate the electrochemical property of $\mathrm{AC}$ and $\mathrm{AC}_{\mathrm{N}}$ using a potentiostat (CH Instrument 600D, Austin, TX, USA). The LSV was scanned from $0 \mathrm{~V}$ to $-1.5 \mathrm{~V}$ under a scan rate of $50 \mathrm{mV} \mathrm{S}^{-1}$. The electrochemical cell used in the experiment had a standard threeelectrode setup, in which the glassy carbon electrode was used as a working electrode, with a $\mathrm{Pt}$ wire and $\mathrm{a} \mathrm{Ag} / \mathrm{AgCl}$ electrode $(+0.197 \mathrm{mV})$ as a counter electrode and a reference electrode, respectively. To better understand the process of hydrogen generation on the catalysts, three different electrolytes with different $\mathrm{pH}$ values were used, including $0.5 \mathrm{M} \mathrm{H}_{2} \mathrm{SO}_{4}, 100 \mathrm{mM}$ PBS (phosphate buffer solution) and $1 \mathrm{M} \mathrm{NaOH}$. The $100 \mathrm{mM}$ PBS solution contains (per L): $\mathrm{K}_{2} \mathrm{HPO}_{4}, 10.7 \mathrm{~g}$; and $\mathrm{KH}_{2} \mathrm{PO}_{4}, 5.3$ $\mathrm{g}$. The catalyst ink was prepared by dissolving $5 \mathrm{mg}$ of catalysts $\left(\mathrm{AC}\right.$ or $\mathrm{AC}_{\mathrm{N}}$ ) in $500 \mu \mathrm{L}$ of Nafion solution (Sigma-Aldrich, St. Louis, MO, USA). An aliquot of $5 \mu \mathrm{L}$ of the ink was pipetted on top of the polished glassy carbon electrode and dried at room temperature before use.

\subsection{MEC setup and operation}

A flat plate MEC reactor was built to study the performance of the prepared HER catalysts for hydrogen production. The anode chamber and the cathode chamber of the MEC had the same working volume, which was $30 \mathrm{~mL}$. The anode chamber and cathode chamber were separated by a piece of cation exchange membrane (Membrane International, Inc., NJ, USA). The anode electrode was a $5 \mathrm{~cm}$ long carbon brush and the anode was inoculated with digester effluent from Southshore wastewater treatment plant (Milwaukee, WI, USA). The cathode electrode was a piece of carbon cloth $(3 \mathrm{~cm} \times 5 \mathrm{~cm})$ on which the catalysts were loaded using Nafion solution as previously described. ${ }^{\mathbf{1 0 , 1 6}}$ The catalyst loading rate on the cathode electrode was $5 \mathrm{mg}$ $\mathrm{cm}^{-2}$. A titanium wire was used as a current collector to connect the cathode electrode to an external circuit that consisted of a DC power supply, which was set at $0.8 \mathrm{~V}$ throughout the experiment, and a $1 \Omega$ resistor. The hydrogen gas produced was collected in a graduated cylinder by water replacement. The anode solution contains (per $\mathrm{L}$ of tap water): sodium acetate, 1 g; $\mathrm{NH}_{4} \mathrm{Cl}, 0.15 \mathrm{~g} ; \mathrm{NaCl}, 0.5 \mathrm{~g} ; \mathrm{MgSO}_{4}, 0.015 \mathrm{~g} ; \mathrm{CaCl}_{2}, 0.02 \mathrm{~g}$; $\mathrm{KH}_{2} \mathrm{PO}_{4}, 0.53 \mathrm{~g} ; \mathrm{K}_{2} \mathrm{HPO}_{4}, 1.07 \mathrm{~g}$; yeast extract, $0.1 \mathrm{~g}$; and trace element, $1 \mathrm{~mL} .{ }^{17}$ The cathode solution contains (per L of tap water): $\mathrm{K}_{2} \mathrm{HPO}_{4}, 10.7 \mathrm{~g}$; and $\mathrm{KH}_{2} \mathrm{PO}_{4}, 5.3 \mathrm{~g}$. At the beginning of each cycle, $200 \mathrm{~mL}$ of fresh anode solution was added into a reservoir and recirculated through the anode chamber at a flow rate of $30 \mathrm{~mL} \mathrm{~min}^{-1}$, while the catholyte was replaced as well but without mixing. The voltage across the resistor was recorded every 5 min using a data acquisition system (Model 2700, Keithley Instruments, Cleveland, OH, USA).

\section{Results and discussions}

\subsection{Electrochemical performance of $\mathrm{AC}_{\mathrm{N}}$}

The morphology of the synthesized $\mathrm{AC}_{\mathrm{N}}$ did not show noticeable changes according to SEM (ESI $\dagger$ ). Fig. 1 presents the LSV curves for the pristine $\mathrm{AC}$ and the $\mathrm{AC}_{\mathrm{N}}$ electrodes in acidic, neutral, and alkaline electrolyte, respectively. One can observe that the $\mathrm{AC}_{\mathrm{N}}$ shows a significantly improved performance for HER in terms of overpotential and current density compared with the pristine AC. The $\mathrm{AC}_{\mathrm{N}}$ exhibited an onset potential at $c a .-0.9 \mathrm{~V}$ in 100 $\mathrm{mM}$ PBS $(\mathrm{pH}=7),-0.8 \mathrm{~V}$ in $0.5 \mathrm{M} \mathrm{H}_{2} \mathrm{SO}_{4}(\mathrm{pH}=0)$, and $-1.0 \mathrm{~V}$ in $1 \mathrm{M} \mathrm{NaOH}(\mathrm{pH}=14)$ of $\mathrm{AC}$, respectively, showing a distinct positive shift relative to the pristine $\mathrm{AC}$, which had an onset potential at $-1.0 \mathrm{~V}$ in $100 \mathrm{mM}$ PBS $(\mathrm{pH}=7),-0.9 \mathrm{~V}$ in $0.5 \mathrm{M}$ $\mathrm{H}_{2} \mathrm{SO}_{4}(\mathrm{pH}=0)$, and $-1.2 \mathrm{~V}$ in $1 \mathrm{M} \mathrm{NaOH}(\mathrm{pH}=14)$. In addition, the $\mathrm{AC}_{\mathrm{N}}$ also showed a higher current density of HER than the pristine AC under the same potential, confirming our hypothesis that nitrogen doping could enhance the catalytic activity of AC towards hydrogen production.

The nitrogen doping treatment encourages the formation of $\mathrm{H}_{\mathrm{ad}}$ from $\mathrm{H}^{+}$and this would have two implications during the hydrogen generation. First, the formation of $\mathrm{H}_{\mathrm{ad}}$ could be more favored and thus facilitate the Volmer step. Second, the facilitated formation of $\mathrm{H}_{\mathrm{ad}}$ might impede the Heyrovsky step and Tafel step, as $\mathrm{H}_{\mathrm{ad}}$ was an reactant in these two steps. However, according to the LSV result, the onset potentials for the HER of 

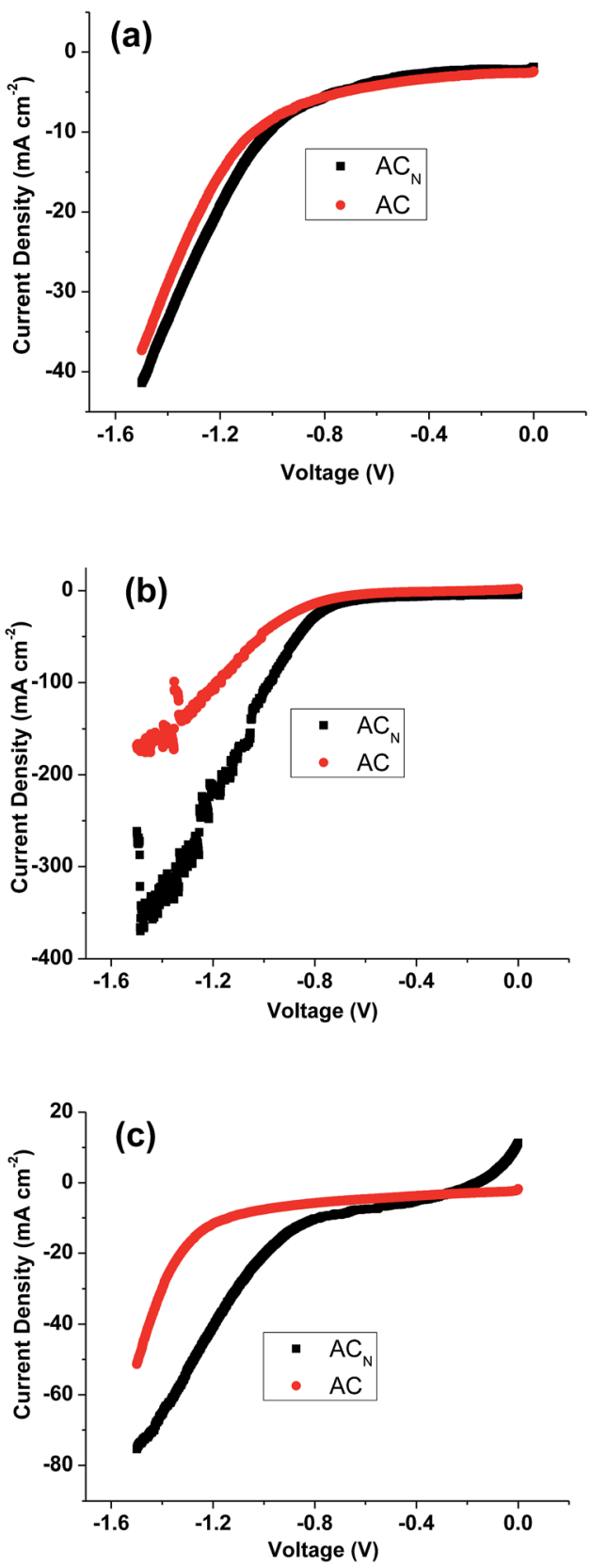

Fig. 1 The LSV tests of $A C_{N}$ and $A C$ : (a) in 100 mM PBS buffer solution, (b) $\mathrm{CV}$ in $0.5 \mathrm{M} \mathrm{H}_{2} \mathrm{SO}_{4}$ solution, and (c) $\mathrm{CV}$ in $1 \mathrm{M} \mathrm{NaOH}$ solution.

$\mathrm{AC}_{\mathrm{N}}$ were consistently more positive than that of pristine $\mathrm{AC}$ in the three electrolytes tested, indicating that the overall effect of nitrogen doping reduced the thermodynamic barrier of hydrogen formation, i.e., the contribution of nitrogen doping towards the Volmer step outweighed its negative impacts on the Heyrovsky step and the Tafel step. Moreover, the increased catalytic activity of $\mathrm{AC}_{\mathrm{N}}$ was more pronounced in the $\mathrm{NaOH}$ solution. One possible explanation is that the Volmer step $\left(\mathrm{H}_{\mathrm{ad}}\right.$ $\leftrightarrow \mathrm{H}^{+}+\mathrm{e}^{-}$) was not limited by the $\mathrm{H}^{+}$that was largely available in the $\mathrm{H}_{2} \mathrm{SO}_{4}$ or PBS solution; however, when the electrolyte was changed to the basic solution, the concentration of $\mathrm{H}^{+}$became so low that the adsorption of $\mathrm{H}^{+}$on the surface of $\mathrm{AC}$ was the rate limiting step, and in this case, an extra energy barrier would have to be overcome so that the HER could proceed. Because $\mathrm{AC}_{\mathrm{N}}$ had increased capacity in forming $\mathrm{H}_{\mathrm{ad}}$, the impact of low $\mathrm{H}^{+}$concentration on the Volmer step was less significant for $\mathrm{AC}_{\mathrm{N}}$, compared with pristine AC. The feature of enhanced formation of $\mathrm{H}_{\mathrm{ad}}$ on $\mathrm{AC}_{\mathrm{N}}$ is of practical importance in MEC operation. In a two chamber MEC, the catholyte $\mathrm{pH}$ increases as hydrogen gas is produced. Thus, an HER catalyst that can operate at high $\mathrm{pH}$ with low extra thermodynamic barrier will allow less frequent replacement of the catholyte or less buffer use, which will translate into lower operational cost for MECs.

Table 1 summarizes the potentials at which the cathodic currents reached $10 \mathrm{~mA} \mathrm{~cm}{ }^{-2}$ in the different electrolytes. The $\mathrm{AC}_{\mathrm{N}}$ consistently exhibited better kinetic performances in catalyzing hydrogen production compared to pristine AC. The potentials needed for the $\mathrm{AC}_{\mathrm{N}}$ cathode to reach $10 \mathrm{~mA} \mathrm{~cm}{ }^{-2}$ were lower than those needed for the pristine AC cathode in all the three electrolytes tested. Furthermore, this difference in potentials was more pronounced in $\mathrm{NaOH}$ solution than the other two electrolytes, which further confirmed our hypothesis that the nitrogen doping could potentially facilitate the Volmer step and the overall HER reaction. It should be noted that the ionic strengths of $\mathrm{H}_{2} \mathrm{SO}_{4}$ and $\mathrm{NaOH}$ solutions were much higher than that of PBS solution, thus more negative potentials were required for the $\mathrm{AC}_{\mathrm{N}}$ and $\mathrm{AC}$ cathodes to reach the same current density $\left(10 \mathrm{~mA} \mathrm{~cm}{ }^{-2}\right)$ than in $\mathrm{H}_{2} \mathrm{SO}_{4}$ and $\mathrm{NaOH}$ solutions; however, this should not be interpreted as hydrogen production was least kinetically favored in a neutral solution.

\subsection{MEC performance}

The current generation of the MEC with different cathode catalysts is shown in Fig. 2. Among the three catalysts tested, the MEC with the $\mathrm{AC}_{\mathrm{N}}$ cathode achieved higher current densities than the one with the $\mathrm{AC}$ cathode. The peak current densities of $\mathrm{AC}_{\mathrm{N}}$ and AC were $0.48 \pm 0.02 \mathrm{~mA} \mathrm{~cm}{ }^{-2}$ and $0.33 \pm 0.03 \mathrm{~mA} \mathrm{~cm}^{-2}$, respectively. This was consistent with the trend obtained in the LSV test. More remarkably, the current density of $\mathrm{AC}_{\mathrm{N}}$ was even comparable to that of $\mathrm{Pt} / \mathrm{C}\left(0.42 \pm 0.04 \mathrm{~mA} \mathrm{~cm}^{-2}\right)$. These results further confirmed that nitrogen doping was an effective approach to enhance the catalytic activity of AC for hydrogen generation.

The rate of the hydrogen gas produced over multiple operating cycles with different catalysts is presented in Fig. 3. The hydrogen generation rates for the $\mathrm{AC}_{\mathrm{N}}$ cathode and the $\mathrm{AC}$ cathode were $0.0030 \pm 0.0004 \mathrm{~m}^{3}$ per $\mathrm{m}^{2}$ per day (normalized by the projected cathode area) and $0.0014 \pm 0.0010 \mathrm{~m}^{3}$ per $\mathrm{m}^{2}$ per day, respectively. Using $T$-test analysis, we confirmed that the $\mathrm{MEC}$ with the $\mathrm{AC}_{\mathrm{N}}$ cathode produced two times of hydrogen gas

Table 1 A list of the potentials (in volts vs. $\mathrm{Ag} / \mathrm{AgCl}$ ) at which the cathodic current densities reached $10 \mathrm{~mA} \mathrm{~cm}{ }^{-2}$

\begin{tabular}{lll}
\hline & $\mathrm{AC}_{\mathrm{N}}$ & Pristine AC \\
\hline $\mathrm{PBS}$ & -1.016 & -1.070 \\
$\mathrm{H}_{2} \mathrm{SO}_{4}$ & -0.625 & -0.750 \\
$\mathrm{NaOH}$ & -0.782 & -1.139
\end{tabular}




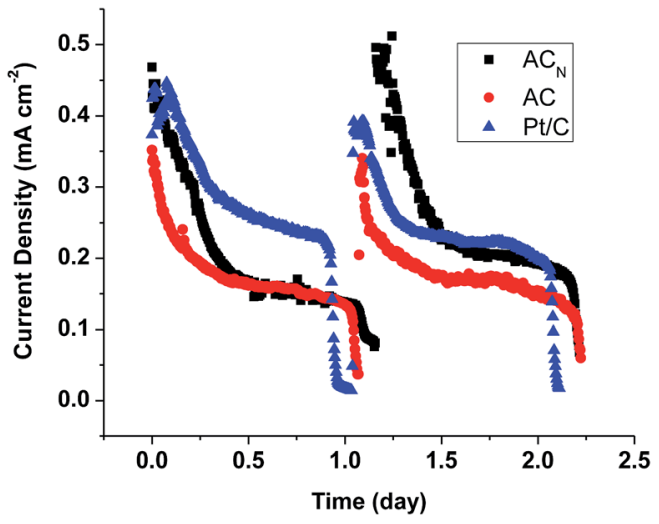

Fig. 2 Current generation in the MEC with different HER catalysts including $\mathrm{Pt} / \mathrm{C}, \mathrm{AC}_{\mathrm{N}}$ and raw $\mathrm{AC}$

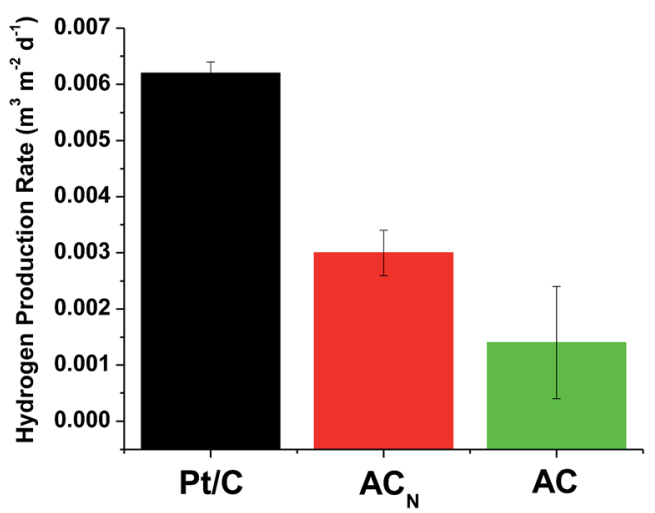

Fig. 3 The hydrogen gas production rate (normalized to the cathode chamber volume) from MEC with different catalysts.

than the one with the AC cathode $(p<0.05)$. In addition, the cathodic efficiency of the $\mathrm{AC}_{\mathrm{N}}$ cathode $(12.25 \pm 1.07 \%)$ was also much higher than that of AC cathode $(7.80 \pm 4.06 \%)$. Higher hydrogen production rate and cathodic efficiency of $\mathrm{AC}_{\mathrm{N}}$ provided further evidence that nitrogen doping was an effective method to improve the AC catalytic activity for hydrogen production in MECs.

Although the MEC with the $\mathrm{AC}_{\mathrm{N}}$ cathode generated similar current densities to the one with the $\mathrm{Pt} / \mathrm{C}$ cathode, the $\mathrm{AC}_{\mathrm{N}}$ cathode produced only half the amount of hydrogen gas that the $\mathrm{Pt} / \mathrm{C}$ cathode produced in MEC (Fig. 3), which was $0.0060 \pm$ $0.0002 \mathrm{~m}^{3}$ per $\mathrm{m}^{2}$ per day. This discrepancy should be attributed to better cathodic efficiency of the $\mathrm{Pt} / \mathrm{C}$, in terms of selective reduction of the target reactants and less energy consumption by catalytic process, both of which require further investigation. Based on the current generation and the hydrogen gas produced, the cathodic efficiency for $\mathrm{Pt} / \mathrm{C}$ and $\mathrm{AC}_{\mathrm{N}}$ were $23.11 \pm$ $1.30 \%$ and $12.25 \pm 1.07 \%$, respectively. Thus, the Pt-based catalysts are still superior in catalyzing HER. However, considering that the cost of as synthesized $\mathrm{AC}_{\mathrm{N}}$ was only $1 / 6$ of the cost of commercial $\mathrm{Pt} / \mathrm{C}$ and that this cost could be further lowered by using cheaper nitrogen precursor, ${ }^{13}$ the $\mathrm{AC}_{\mathrm{N}}$ could be a promising alternative HER catalyst to $\mathrm{Pt} / \mathrm{C}$ in larger scale MECs.

\section{Conclusions}

In this study, we have demonstrated that the nitrogen doping process could increase the capability of AC for hydrogen evolution reaction. The nitrogen doping enhanced the formation of $\mathrm{H}_{\mathrm{ad}}$ on $\mathrm{AC}$, which facilitated the Volmer step, and reduced the energy barrier for hydrogen generation, especially under a high pH situation. When being employed in an MEC as a cathode catalyst, both the hydrogen production and cathodic efficiency of $\mathrm{AC}_{\mathrm{N}}$ were higher than those of pristine $\mathrm{AC}$. The increased catalytic activity together with the low cost of $\mathrm{AC}_{\mathrm{N}}$ makes it a promising HER catalyst. Future research will need to further reduce the cost of $\mathrm{AC}_{\mathrm{N}}$ through optimizing the doping procedure and using cheaper nitrogen precursors, and to examine its stability for long-term operation of MECs.

\section{Notes and references}

1 H. Liu, R. Ramnarayanan and B. E. Logan, Environ. Sci. Technol., 2004, 38, 2281-2285.

2 B. E. Logan, D. Call, S. Cheng, H. V. M. Hamelers, T. H. J. A. Sleutels, A. W. Jeremiasse and R. A. Rozendal, Environ. Sci. Technol., 2008, 42, 8630-8640.

3 D. F. Call, M. D. Merrill and B. E. Logan, Environ. Sci. Technol., 2009, 43, 2179-2183.

4 A. Tenca, R. D. Cusick, A. Schieuano, R. Oberti and B. E. Logan, Int. J. Hydrogen Energy, 2013, 38, 1859-1865.

5 A. Kundu, J. N. Sahu, G. Redzwan and M. Hashim, Int. J. Hydrogen Energy, 2013, 38, 1745-1757.

6 Y.-X. Huang, X.-W. Liu, X.-F. Sun, G.-P. Sheng, Y.-Y. Zhang, G.-M. Yan, S.-G. Wang, A.-W. Xu and H.-Q. Yu, Int. J. Hydrogen Energy, 2011, 36, 2773-2776.

7 A. W. Jeremiasse, H. V. M. Hamelers, M. Saakes and C. J. N. Buisman, Int. J. Hydrogen Energy, 2010, 35, 1271612723.

8 J. C. Tokash and B. E. Logan, Int. J. Hydrogen Energy, 2011, 36, 9439-9445.

9 Y. Hou, B. Zhang, Z. Wen, S. Cui, X. Guo, Z. He and J. Chen, J. Mater. Chem. A, 2014, 2, 13795-13800.

10 L. Xiao, Z. Wen, S. Ci, J. Chen and Z. He, Nano Energy, 2012, 1, 751-756.

11 K. Krischer and E. R. Savinova, in Handbook of Heterogeneous Catalysis, Wiley-VCH Verlag GmbH \& Co. KGaA, 2008.

12 L. Zhang and Z. Xia, J. Phys. Chem. C, 2011, 115, 1117011176.

13 B. Zhang, Z. Wen, S. Ci, S. Mao, J. Chen and Z. He, ACS Appl. Mater. Interfaces, 2014, 6, 7464-7470.

14 H. Sontheimer, J. C. Crittenden and R. S. Summers, Activated carbon for water treatment, DVGW-Forschungsstelle, EnglerBunte-Institut, Universitat Karlsruhe (TH), 1988.

15 V. Gupta, B. Gupta, A. Rastogi, S. Agarwal and A. Nayak, Water Res., 2011, 45, 4047-4055.

16 S. Yossan, L. Xiao, P. Prasertsan and Z. He, Int. J. Hydrogen Energy, 2013, 38, 9619-9624.

17 Z. He, N. Wagner, S. D. Minteer and L. T. Angenent, Environ. Sci. Technol., 2006, 40, 5212-5217. 